\title{
Research on Three Social Interaction Model Used in Community Governance-Taking Chengdu Yudong Community as an Example.
}

\author{
Sha Wen \\ Public Administration and Law School, Southwest Jiaotong University, Chengdu, China \\ wen@jodjod.com
}

Keywords: Community governance; Social organization; Social worker; Residents; Interaction

\begin{abstract}
Nowadays, community governance faces problems such as the weak consciousness of participation in residents, lack of social workers and immature social organizations etc. Positively exploring Three Social Interaction, which is based on the community, social organizations as the carrier and social team workers as the backbone, Yudong community promote the development level of community construction and provide a full range of services for the residents under the Interaction. The model partially solved the outstanding problems in the current community governance, which provides a reference for the further development of community governance. There are some viable measures to be adopted such as building a management platform of social organizations, encouraging all kinds of social organizations to settle in and constructing a self-governance model in residents.
\end{abstract}

\section{Introduction}

At present, our country is in the stage of rapid development of new urbanization. Community governance has become the key problem because of a large number of flowing populations and the construction of rural concentrated settlements. Social organizations become the creators of consensus conflict mediator, arbitrator and service providers in Community governance work [1]. Hu Jintao General Secretary pointed out that "improve the leadership of the Party, governmental responsibility, social collaboration, public participation in social management structure" [2] on February 19, 2011.Community governance need the strong participation of social organization. Therefore, the society actively explored new model of social organizations to join in community governance. The participation models of social organizations in community governance in our country are the agent execution model and the dual governance model mainly [3]. For example, Changshou model is constructed on the basis of the building of the party as a leader, hub management as a support and government purchase as new impetus [4]. Even if the community has carried out many explorations, there are problems such as the weak consciousness of participation in residents, lacking social workers, immature social organizations etc. It's difficult to meet the increasingly complex needs of the residents.

Subsequently, Chengdu has explored the diversification of community governance. Pilot projects were run in two communities of Wenjiang in 2012.And the model has been introduced in 21 communities of Chengdu in April 2013 [5]. The model affirms the important status of social organizations in community governance and has achieved noticeable results in the construction of model, the diversification of body and the improvement of service levels. Therefore, studying the specific practices of Three Social Interaction can contribute to community development.

\section{Three Social Interaction Model of Yudong Community}

Yulin East community, Yulin street, Wuhou District, Chengdu, Sichuan province, founded in December 2001, is located in the urban areas of Chengdu's center, whose surrounding facilities is completed. So, attentions are paid in community buildings.

Since promoting the Three Social Interaction model in Chengdu city in 2013, communities have actively practiced the model. At the same time, communities keep exploring and improving. Three social interactions include the community, social organizations and social workers. Community, the leading role of the structure, refers to the community party committee and community committee. 
Social organizations refer to non-profit organizations sharing community affairs with community committees and settling legally. Social workers refer to professional knowledge, literacy or skills of social work, which is unrestricted to the social organizations or the social workers. The heart of Three Social Interaction model (Fig. 1) is interacting favorably and servicing residents. Social workers provide professional skills for social organizations and community; community and social organizations cultivate more social workers in practice and provide diversified services for the residents; community also provides resources and guidance for social organizations.

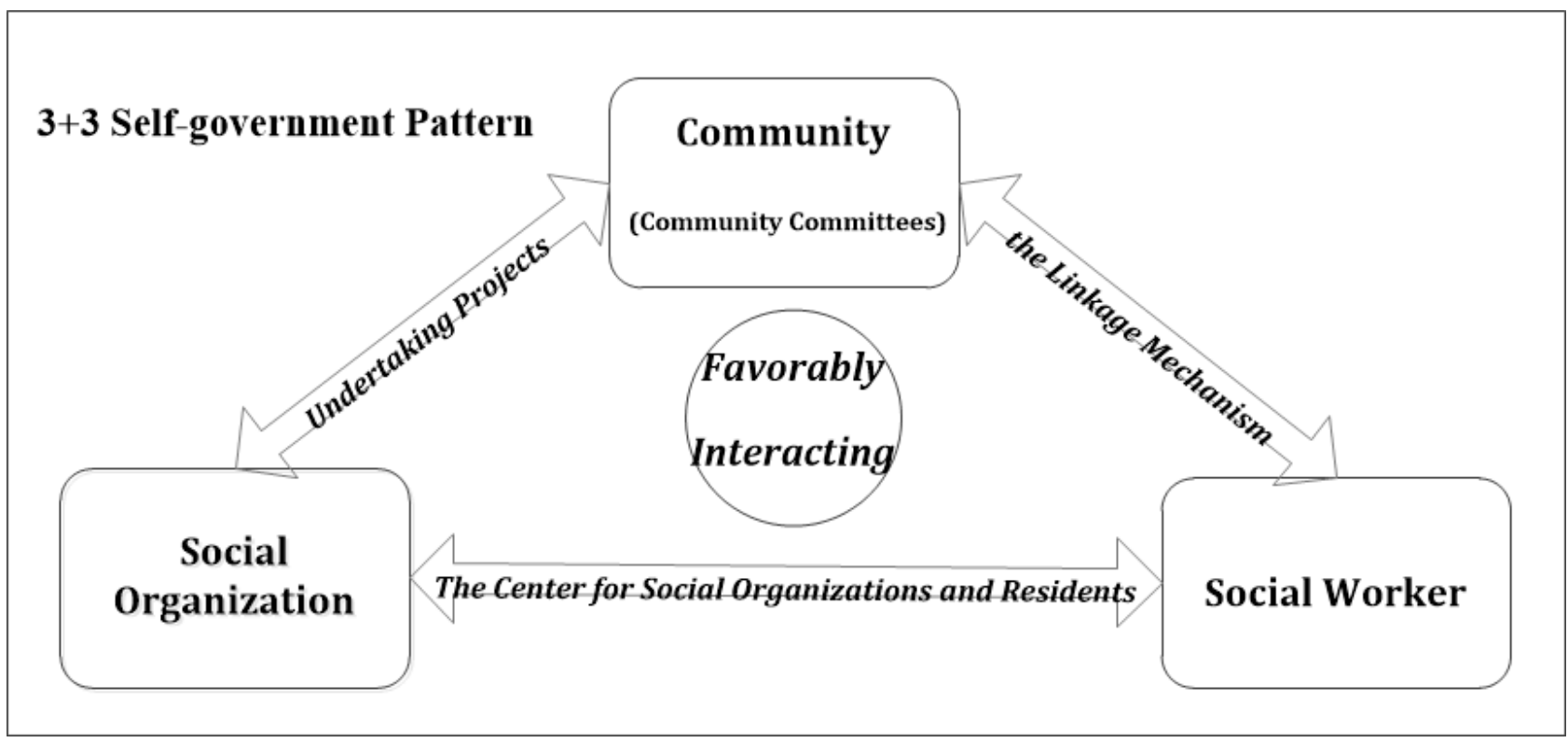

Figure 1. Three Social Interaction Model of Yudong Community

3+3 Self-government Pattern is an important way of enhancing the ability of residents' self-government. It's also one of the aspects of promoting the diversification of community governance. The pattern promotes self-government in three aspects: community leadership, autonomous mechanism and grass-roots policy. And each aspect is divided into three parts. $3+3$ has promoted residents' participation in community activities and affairs and laid a certain foundation for Three Social Interaction.

Community and Social Organization. Community is the supporter of social organization, and the social organization is a supplement to community. In Yudong community, social organizations service residents by undertaking various types of projects. Most of projects are proposed by community committees, and then undertaken by social organizations according to their own abilities. And the small part is developed by social organizations. At the same time, Wuhou District Xinhang Social Work Servicing Center also undertakes 139 governmental services of community. According to the survey, social organizations provide care for the elderly, protection of children's rights and interests, services for the disabled, charity assistance and other diversified service for the residents [6]. Thus, social organizations play an increasingly important role. Through the cooperation between party committee and community, the self-management of social organizations and the broad participation of the residents, all kinds of community resources are effectively integrated and a long-term working mechanism of community service is actively built.

Community and Social Worker. Social workers provide the community with professional ways, methods and concepts and also enhance the level of service; the community provides a developing platform for social workers. Yudong has laid the groundwork for community service by introducing the linkage mechanism that means social workers leading volunteers and volunteers helping social workers. Social work service center includes Lichuan and Xinhang within Yudong; there is 6 staff with social qualifications accounting for $75 \%$ in community committees. In the course of the project, social workers and volunteers learn from each other, social workers continuously develop and grow. On the other hand, the community provides the residents with more practical services by applying 
social work knowledge to community works. For lots of elderly and children, the community has established a poverty alleviation system to protect children, flexible Home Care system and disabled charity care platform.

Social Organization and Social Worker. As the same, social workers provide professional perspective and leading for social organizations; social organizations cultivate more professional social workers. Social organizations and social workers could interact effectively through center for social organizations and residents, East Yulin.The center is the platform established by the sub-district office and the community for better achieving of Three Social Interaction. This platform is not only the interaction within one social organization, also cross-interaction between the social organizations so as to enable a rapid development of social organizations' professionalism and social workers. According to the survey, there is one professional social worker within every social organization at least. And there are 10 within Xinhang.Under the helping of Xinhang, social organizations of Yudong applied 7 projects of civil administration bureau in 2014 [7]. Social organizations favorably interact with social workers to promote common development.

\section{Results of Three Social Interactions}

Capacity Advancement of Social Organizations. Benefitting from the interaction between social workers, social organizations and the community, Yudong has increasingly specialized in providing services to residents, also trained a group of social workers. The community carries out projects for cultivating and developing social organizations, and the center provides professional development platform. Through the center, abilities of social organizations have been effectively improved, and staff are also actively becoming a professional social worker under the guidance of Xinhang.

Mainly Diversified Formation. From a horizontal perspective, social organizations, the groups within Yudong and residents all participate in community building in varying degrees. In recent years, the community has introduced a total of 18 social organizations. Party branch and the groups have serviced the residents. At the same time, the residents are gradually realizing the self-management, self-service and self-education [8]. From a vertical perspective, Yudong promotes the residents' self-governance through $3+3$ while cultivating and introducing social organizations.

Meeting the Multiple Needs. With the accelerated process of China's social development, the demand of community residents is increasingly extensive. Not only includes the daily needs, but also including welfare, cultural education and so on [9]. Social organizations make contributes to culture construction of the community through combining community needs and making full use of community resources in Yudong.For example, Mulin Art Group, Heart Vision of Photography and Association of Sichuan and other social organizations carry out activities for the residents of a rich extra-curricular life.

\section{Conclusions}

Social organizations, government and the masses are the key of social organizations participation in the practice of building community governance model [10]. Three Social Interaction in Yudong community has a certain referential significance. With the advantages of encouraging a variety of social organizations to settle in and providing diverse services to the residents, building management platform of social organization is helpful to make social organizations stronger and introduce specialists. On the other hand, it's necessary to construct a self-governance model in residents to encourage residents to take part in community governance and raise the degree of community autonomy.

\section{References}

[1] R.H. Tan: Journal of Shaoyang University (Social Science Edition), Vol. 13 (2014) No.5, p.65-70. (In Chinese)

[2] J.T. Hu: Journal of Party Building, (2011) No.3, p. 4-7. (In Chinese) 
[3] H. Deng: Journal of the Party School of CPC Xiamen Municipal Committee, (2014) No.6, p. 26-31. (In Chinese)

[4] Y. Luo: Journal of Theory and Reform, (2009) No.4, p. 80-83. (In Chinese)

[5] Information on http://www.sc.gov.cn/10462/10464/10465/10595/2013/4/18/10257066.shtml

[6] Information on http://jcpt.chengdu.gov.cn/wuhouqu/yulindonglushequ/Information on http://www.cdmzj.gov.cn/cdmz/zwgk/gggs/E44825738163468589C0AF7F7AD71129.html

[7] P.L. He: Journal of Shanghai University (Social Sciences), (2009) No.4, p. 20-31. (In Chinese)

[8] X.H. Pan, Y.J. Gong: Journal of Zhejiang Normal University (Social Sciences), Vol. 39 (2014) No.4, p. 79-84. (In Chinese)

[9] J.Z. Xia: Research on the Governance Structure of Urban Community in China (Beijing: Renmin University of China Press, China 2012). (In Chinese) 